\title{
Airborne Wind Profiling Algorithms for the Pulsed 2-Micron Coherent Doppler Lidar at NASA Langley Research Center
}

\author{
Jeffrey Y. Beyon ${ }^{1}$, Grady J. Koch ${ }^{2}$, Michael J. Kavaya ${ }^{3}$, and Taylor J. Ray ${ }^{4}$ \\ ${ }^{1}$ NASA Langley Research Center, MS 488, Hampton, VA 23681, USA, Jeffrey.Y.Beyon@nasa.gov \\ ${ }^{2}$ NASA Langley Research Center, MS 468, Hampton, VA 23681, USA, Grady.J.Koch@nasa.gov \\ ${ }^{3}$ NASA Langley Research Center, MS 468, Hampton, VA 23681, USA, Michael.J.Kavaya@nasa.gov \\ ${ }^{4}$ Electrical Engineering Department, Colorado School of Mines, Golden, CO 80401, USA, taray@mymail.mines.edu
}

\begin{abstract}
Two versions of airborne wind profiling algorithms for the pulsed 2-micron coherent Doppler lidar system at NASA Langley Research Center in Virginia are presented. Each algorithm utilizes different number of line-of-sight (LOS) lidar returns while compensating the adverse effects of different coordinate systems between the aircraft and the Earth. One of the two algorithms APOLO (Airborne Wind Profiling Algorithm for Doppler Wind Lidar) estimates wind products using two LOSs. The other algorithm utilizes five LOSs. The airborne lidar data were acquired during the NASA's Genesis and Rapid Intensification Processes (GRIP) campaign in 2010. The wind profile products from the two algorithms are compared with the dropsonde data to validate their results.
\end{abstract}

Keywords: Wind profile algorithm, coherent lidar, GRIP, DAWN AIR

\section{INTRODUCTION}

The coherent Doppler wind lidar system DAWN (Doppler Aerosol Wind Lidar) developed at NASA Langley Research Center (LaRC) has flown on DC8 during the NASA's Genesis and Rapid Intensification Processes (GRIP) campaign in 2010 [1, 4-5], and on UC12B during the DAWN flight demonstration campaign in 2012. The predecessor of DAWN is ground-based VALIDAR (Validation Lidar), which has been operating in a trailer since 2000 [6-17]. In order to process the airborne data from DAWN, NASA LaRC has developed two versions of airborne wind profiling algorithms to process the data acquired from these two campaigns. The comparisons of the two algorithms in design and performance are the main focus of this paper. The results of wind profiling are compared in graphs to show the strength of each algorithm. Panoramic displays of continuous observation of wind profiles are helpful in understanding the wind trend and validating analysis results. Samples of such displays are presented using the DAWN data from UC12B.

\section{PROJECT DAWN AND AIR CAMPAIGNS}

DAWN is a pulsed 2-micron coherent Doppler lidar system at NASA LaRC. Its data acquisition, processing, and display system (DAPDS) estimates wind parameters by measuring the frequency shift in lidar back scatters while providing range information. DAWN flew during the GRIP hurricane campaign on DC8, which flew out of Fort Lauderdale, FL. The total flight time of DAWN during the GRIP was approximately 130 hours. DAWN was one of many other science missions onboard DC8, and the goal of DAWN was to test the airborne wind profiling capabilities of the system. The second flight demonstration on UC12B was based at LaRC in 2012. Flight tests on the UC-12B centered on evaluating the installation of DAWN into a smaller aircraft and in the high vibration environment associated with turboprop engines. DAWN operated in 22 hours of flights on the UC-12B.

\footnotetext{
${ }^{1}$ Jeffrey.Y.Beyon@nasa.gov; phone 1757 864-4249; fax 1757 864-7944; www.nasa.gov
} 

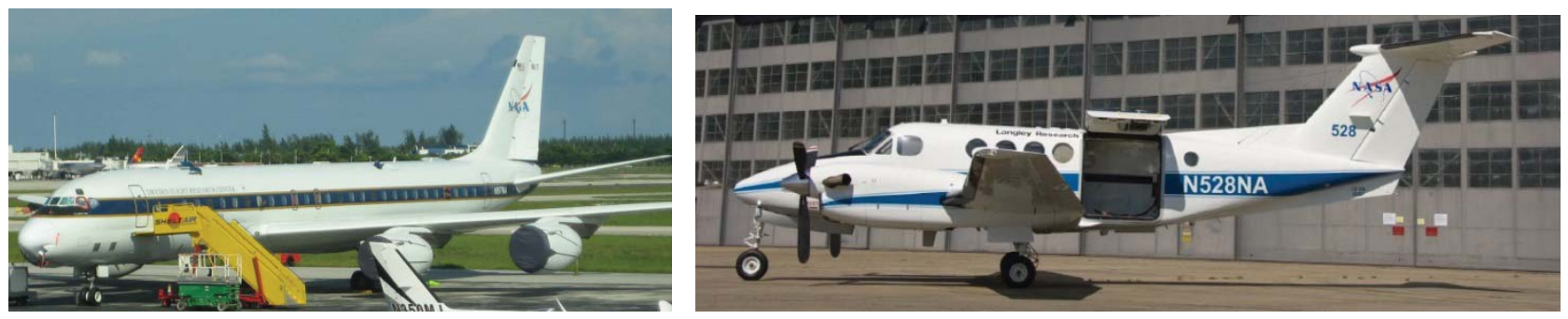

Fig. 1. NASA's DC-8 for GRIP campaign (August, 2010) and UC-12B for DAWN flight demo campaign (October, 2012).

\section{AIRBORNE WIND PROFILING ALGORITHMS}

In order to process the airborne wind lidar data from DAWN, two versions of airborne wind data analysis algorithms have been developed at LaRC. Both algorithms have been integrated and operational in both the real-time data acquisition and processing software (DAPS) and the post-processing software DAPS-LV [2], where DAPS was built in $\mathrm{C}$ and DAPS-LV in LabVIEW. Both the first algorithm APOLO and the second algorithm can process airborne wind lidar data real-time so that DAPS can display instantaneous wind profiles as well as long-haul wind trend observations during a mission airborne. Each algorithm has the capability of instrument offset compensation, which is a critical process to accurate wind parameter estimation. Such instrument offsets stem from a variety of sources such as INS/GPS (Inertial Navigation System/Global Positioning System) unit misalignment, lidar telescope misalignment, and scanner installation bias. Both APOLO and the second algorithm have a separate routine to estimate offset angles using groundreturn lidar data to compensate their adverse effects to accurate wind parameter estimates. The offset compensation routines for each algorithm are entirely independent of each other except the basic principle of minimization of mean square errors in a multivariate system. In algorithm development, the accurate translation of different coordinate systems was also critical to interpret algorithm products properly. The challenge lies in understanding airborne wind data between Earth coordinates (east, north, and up or down) and aircraft body coordinates. The details of the derivation of each algorithm, however, are not the goal of this paper, and will be postponed to a future paper.

\section{ALGORITHM COMPARISIONS}

\begin{tabular}{|c|c|c|c|}
\hline & Algorithm 1 (APOLO) & Algorithm 2 & Comments \\
\hline No of LOS & 2 & 5 & $\begin{array}{l}\text { The two LOSs for APOLO are } 90 \\
\text { degrees apart (-45 and } 45 \text { degrees). } \\
\text { The five LOSs for the second } \\
\text { algorithm are equally divided between } \\
-45 \text { degrees and } 45 \text { degrees. ( } 0 \text { degree } \\
\text { is straight ahead of the plane and left } \\
\text { being negative.) }\end{array}$ \\
\hline $\begin{array}{l}\text { Offset Angle } \\
\text { Count }\end{array}$ & 5 & 5 & $\begin{array}{l}\text { Examples are roll, pitch, yaw, and the } \\
\text { telescope mount bias angles. }\end{array}$ \\
\hline Advantages & $\begin{array}{l}\text { No inverse involved so less } \\
\text { susceptible to noise. Simple } \\
\text { vector sum is the principle. }\end{array}$ & $\begin{array}{l}\text { Use of all five LOSs. } \\
\text { Calculates vertical } \\
\text { component of wind vector. }\end{array}$ & $\begin{array}{l}\text { Algorithm } 2 \text { involves solving for } \\
\text { unknowns given more equations using } \\
\text { pseudo-inverse. }\end{array}$ \\
\hline Disadvantages & $\begin{array}{l}\text { Not using all five LOSs. } \\
\text { Assumes vertical wind } \\
\text { component is zero. }\end{array}$ & $\begin{array}{l}\text { Sensitive to noise due to } \\
\text { pseudo-inverse computation. }\end{array}$ & \\
\hline
\end{tabular}

Table 1. Comparison of the two airborne wind profiling algorithms developed at NASA Langley Research Center.

Table 1 compares APOLO with the second algorithm in different categories. APOLO utilizes two LOSs that are 
perpendicular to each other while Algorithm 2 uses all five LOSs. The offset estimation routines for each algorithm are not similar to each other and the definition of offset angles is different in each algorithm, too. The table only shows the number of offset angles in each algorithm. APOLO is based on vector sum to estimate wind parameters while Algorithm 2 uses pseudo-inverse to find unknowns (wind parameters) using more given equations.
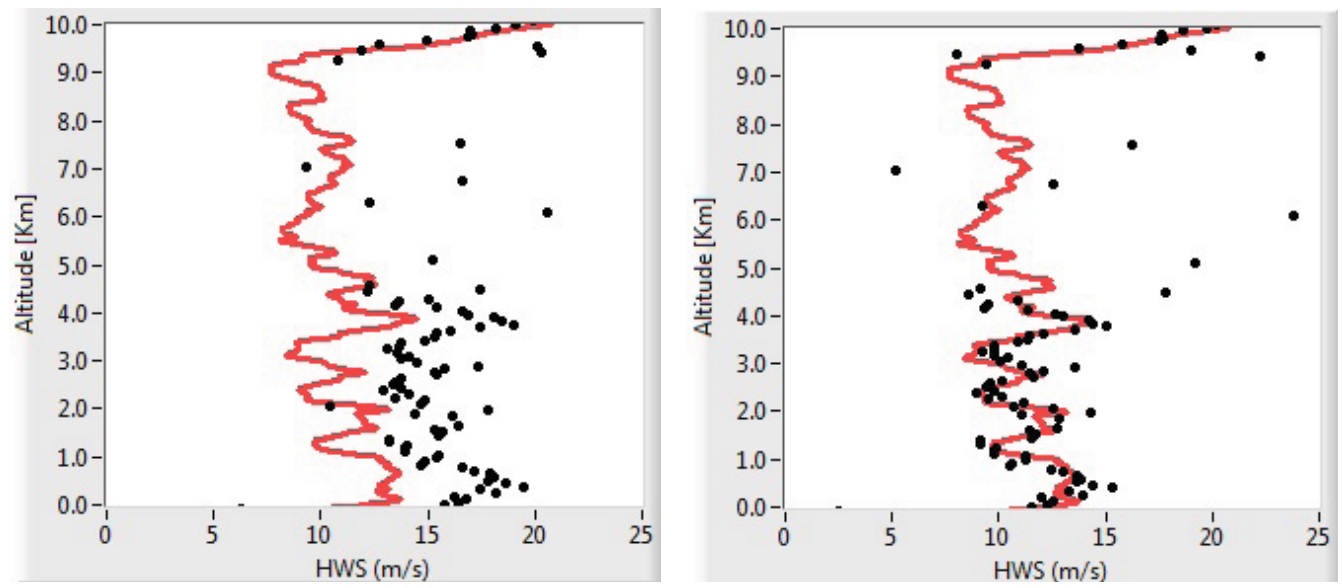

Fig. 2. Offset compensation comparison in HWS. Algorithm = APOLO. Data on September 1, 2010 during the GRIP mission on DC8. FFT size $=4096$ with zero padding. Altitude $=10,608$ meters. Left without offset compensation. Right with offset compensation. Red line represents dropsonde data, and black dots are the estimates from APOLO.

Figure 2 shows the result of offset compensation in horizontal wind speed (HWS) from APOLO. The data were acquired on September 1, 2010 on a DC8 while it was at 10,608 meters in altitude. A total of 512 samples were used to represent wind at each altitude, and a 4,096-point FFT was used to process each set of 512 samples using zero padding. It clearly shows the effectiveness of offset compensation with APOLO. The APOLO estimates near $4.5-9 \mathrm{~km}$ in altitude are erroneous due to low received signal backscatter associated with a damaged receiver component and atmospheric conditions of low aerosol content. The solid red line is the dropsonde measurement only for a reference purpose, and not to imply which measurements are more accurate (the two sensors measure different volumes over different time scales). The good agreement on the right plot means that the wind was slowly varying over the dropsonde fall time and over the distance of DC-8 movement for the lidar measurement time. This agreement is not guaranteed in a general wind field. When it does fortunately occur, it permits comparison of processing algorithms.
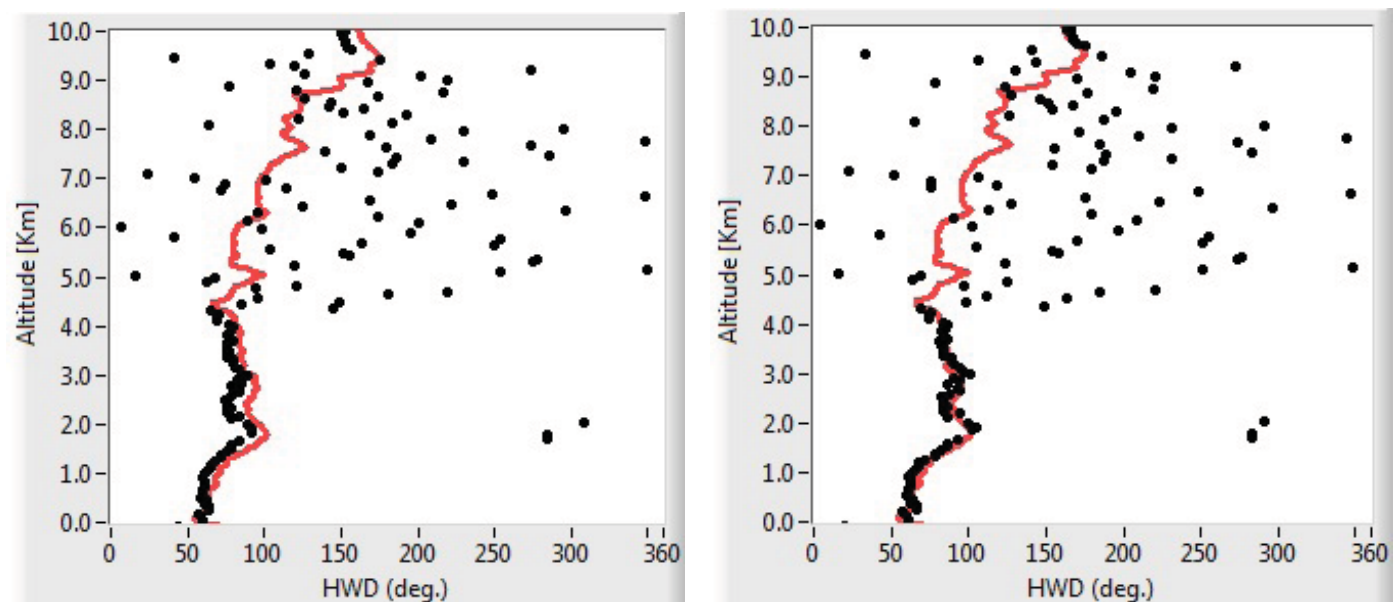

Fig. 3. Offset compensation comparison in HWD. Algorithm = APOLO. Data on September 1, 2010 from the GRIP mission on DC8. FFT size $=4096$ with zero padding. Altitude $=10,608$ meters. Left without offset compensation. Right with offset compensation. Red line represents dropsonde data, and black dots are the estimates from APOLO. 
Figure 3 shows the result of offset compensation in horizontal wind direction (HWD) from APOLO. The data are the same as Figure 2. The adverse effects of a low Signal-to-Noise-Ratio (SNR) are clear near $4.5-9 \mathrm{~km}$ in altitude.

The results of offset compensation in both HWS and HWD from the second algorithm didn't show any difference, so they are not shown to compare the effectiveness of offset compensation. However, HWS and HWD of Algorithm 2 are shown to compare with those of APOLO in Figures 4 and 5.
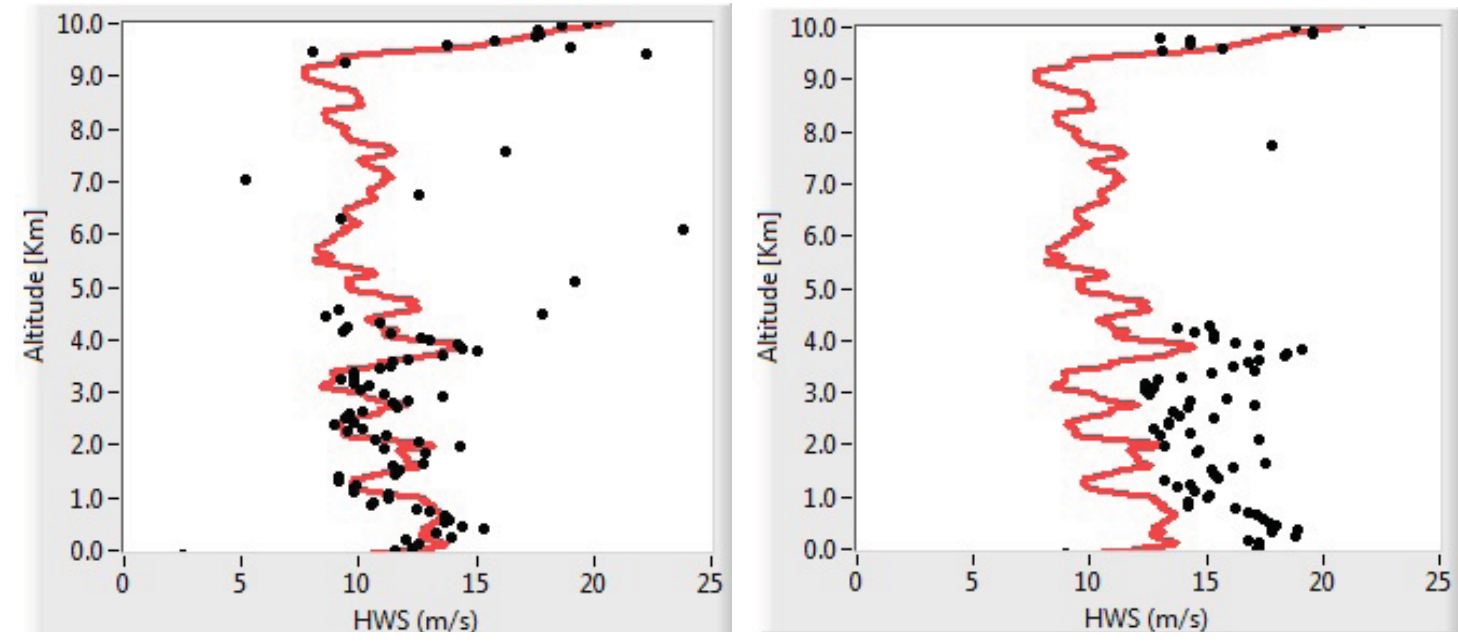

Fig. 4. HWS from APOLO (algorithm 1 - left) and Algorithm 2 (right). Offset compensation was applied. Data on September 1, 2010 during the GRIP mission on DC8. FFT size $=4096$ with zero padding. Altitude $=10,608$ meters. Red line represents dropsonde data, and black dots are the estimates from APOLO (left) and Algorithm 2 (right).

Figure 4 compares HWS from APOLO (left) with that from Algorithm 2 (right). The same data were used in this comparison, and dropsonde measurements are shown for a reference purpose again. Figure 5 compares HWD in the same fashion.
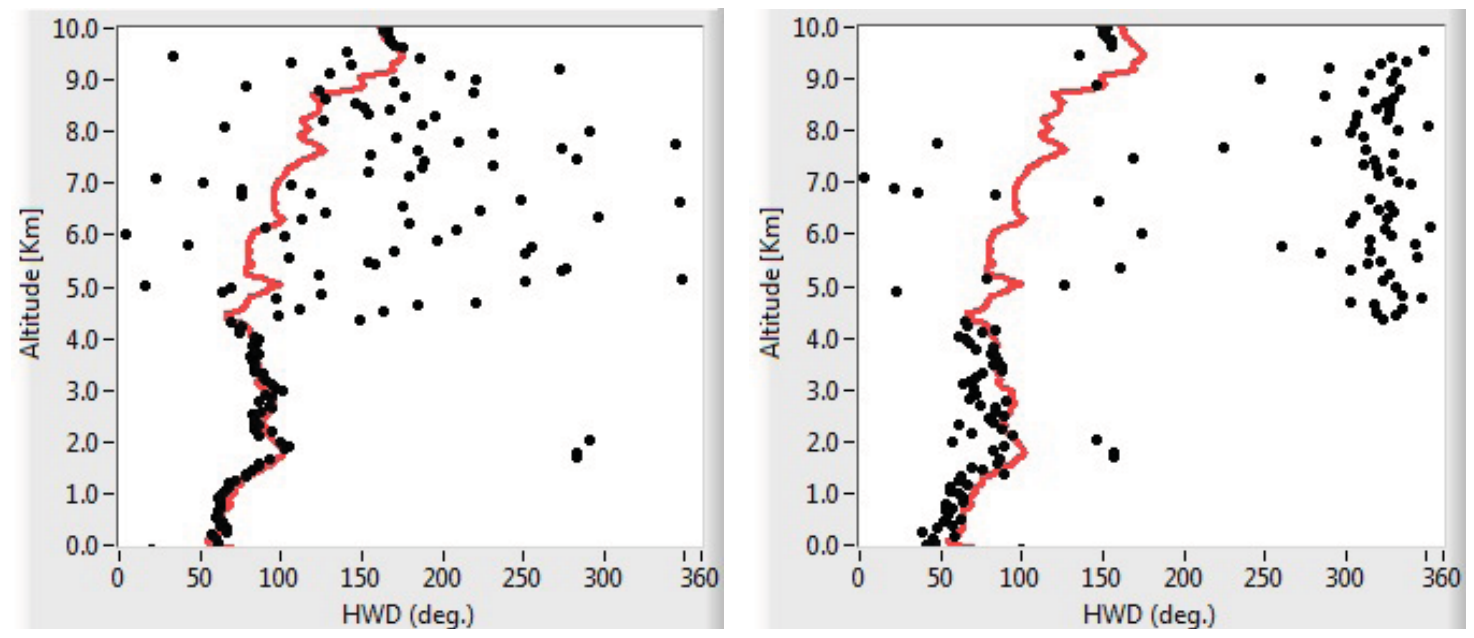

Fig. 5. HWD from APOLO (algorithm 1 - left) and Algorithm 2 (right). Offset compensation was applied. Data on September 1, 2010 during the GRIP mission on DC8. FFT size $=4096$ with zero padding. Altitude $=10,608$ meters. Red line represents dropsonde data, and black dots are the estimates from APOLO (left) and Algorithm 2 (right).

Figures 6-8 show panoramic displays of power, HWS, and HWD during the DAWN flight demonstration in 2012. DAWN was integrated in a NASA UC12B aircraft and flew at lower altitudes than the GRIP hurricane campaign. The time stamps are in Zulu time and the images were generated in software developed in LabVIEW for post processing. Such software utilizes the output data from DAPS or DAPS-LV to create a long-haul observation displays as shown 
here.

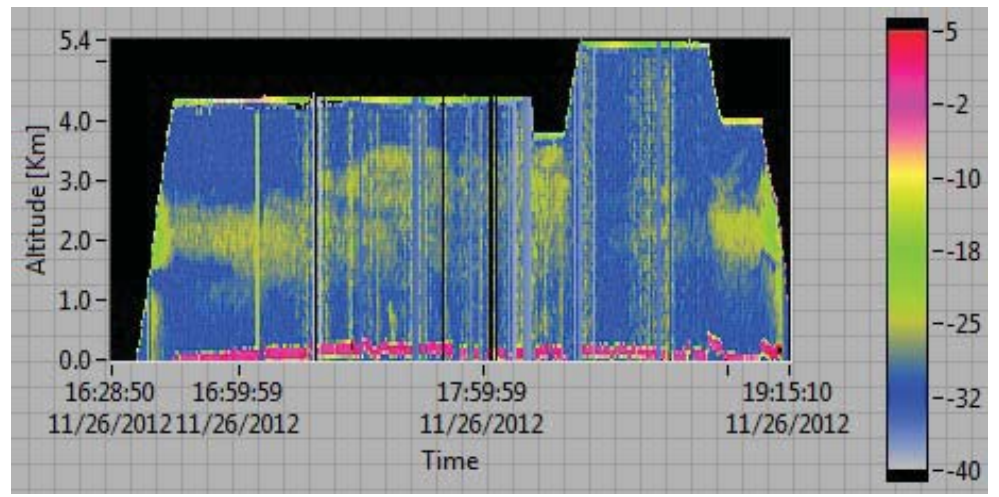

Fig.6. Panoramic display of power distribution from the flight campaign on UC12B. Algorithm $=$ APOLO. Offset compensation was applied. Data acquired on November 26, 2012. FFT size $=512$.

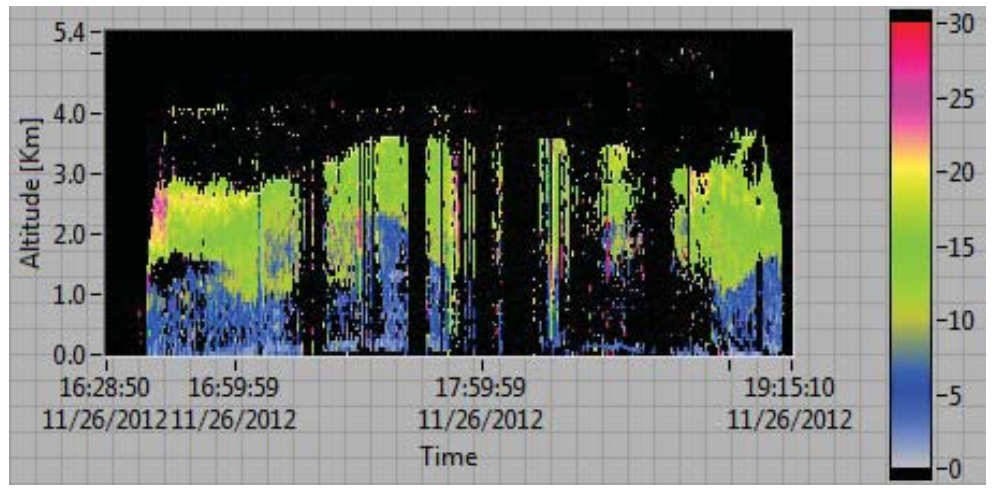

Fig. 7. Panoramic display of HWS from the flight campaign on UC12B. Algorithm = APOLO. Offset compensation was applied. Data acquired on November 26, 2012. FFT size $=512$.

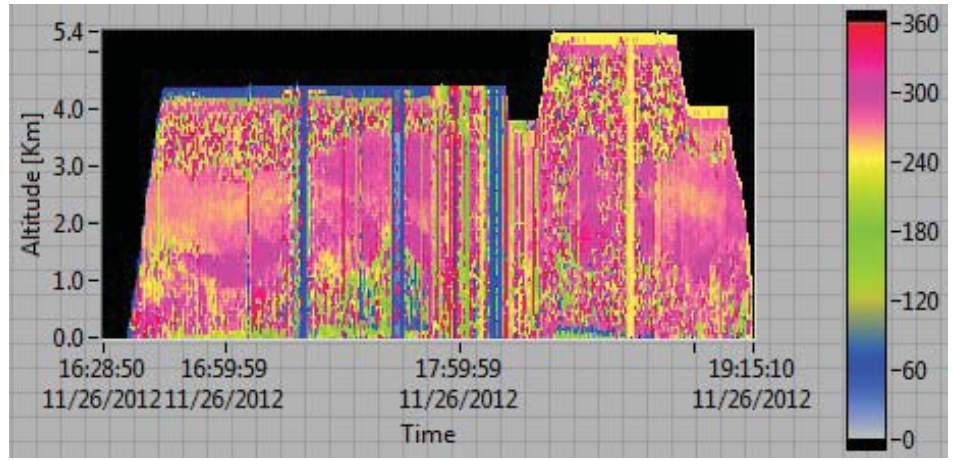

Fig. 8. Panoramic display of HWD from the flight campaign on UC12B. Algorithm = APOLO. Offset compensation was applied. Data acquired on November 26, 2012. FFT size $=512$.

The aircraft flight track on this day was from Hampton, Virginia to Charlotte, North Carolina and back. While over Charlotte the aircraft made multiple overpasses of a ground-based wind profiling radar for comparing the measurements of the two sensors. The power spectral density time trend of Figure 6 reveals cloud and aerosol structure through the course of the flight with an aerosol layer evident from 1.5 to $3.5-\mathrm{km}$ altitude throughout most of the flight. The horizontal wind speed trend of Figure 7 shows a horizontal wind magnitude vertical shear at around 1-km altitude, typical of the transition from the atmospheric boundary layer (where the wind speed is about $5-\mathrm{m} / \mathrm{s}$ in this case) to the free troposphere (where the wind speed is about $15-\mathrm{m} / \mathrm{s}$ in this case). The wind direction plot of Figure 8 shows a wind 
direction from the northwest in the free troposphere above 1-km altitude, but a more southerly direction in the low altitudes in the more turbulent atmospheric boundary layer below 1-km altitude, a horizontal wind direction vertical shear.

\section{CONCLUSION}

The comparisons of two airborne wind profiling algorithms developed at NASA LaRC are reviewed in this paper. Some notable challenges in the development of these algorithms are instrument offset compensation and accurate understanding of data in different coordinates such as Earth coordinates and aircraft body coordinates. Offset estimation is based on minimum mean square error principle. Dropsonde data are used for a reference purpose to show the impact of offset compensation onto HWS and HWD from APOLO. The second algorithm doesn't seem to show any difference with offset compensation applied to HWS and HWD. APOLO is based on simple vector sum while Algorithm 2 is based on solving linear equations with less unknown than the number of given equations. APOLO assumes zero vertical wind speed whereas Algorithm 2 does not. Both APOLO and Algorithm 2 are in DAPS and DAPS-LV and have been operational since 2010. They continue to evolve with enhancements and more features such as faster data processing via optimized codes and the integration of ground-based lidar data processing capability.

\section{ACKNOWLEDGMENT}

The authors are grateful for support from NASA Science Mission Directorate (SMD), the SMD Airborne Instrument Technology Transition program, the NASA SMD Earth Science Technology Office (ESTO) Instrument Incubator Program, the ESTO Laser Risk Reduction Program, Langley Research Center (LaRC), and the LaRC Engineering Directorate.

\section{BIBLIOGRAPHY}

[1] M. J. Kavaya, J. Y. Beyon, G. J. Koch, M. Petros, P. J. Petzar, U. N. Singh, B. Trieu, and J. Yu, "The DAWN Airborne, Wind-Profiling, Coherent-Detection Lidar System: Overview, Flight Results, and Plans," Journal of Atmospheric and Oceanic Technology (JTECH), SUBMITTED December, 2012.

[2] J. Y. Beyon, G. J. Koch, and M. J. Kavaya, "Airborne Wind Profiling with the Data Acquisition and Processing System for a Pulsed 2-Micron Coherent Doppler Lidar System," in Proc. of the Defense and Security Symposium 2012 (8379-22), Baltimore, MD, April, 2012.

[3] J. Y. Beyon, G. E. Arthur, G. J. Koch, and M. J. Kavaya, "Noise Whitening in Airborne Wind Profiling with a Pulsed 2-Micron Coherent Doppler Lidar at NASA Langley Research Center," in Proc. of the Defense and Security Symposium 2012 (8379-23), Baltimore, MD, April, 2012.

[4] J. Y. Beyon, G. J. Koch, and M. J. Kavaya "Development of the Data Acquisition and Processing System for a Pulsed 2-Micron Coherent Doppler Lidar System," in Proc. of the SPIE Asia-Pacific Remote Sensing (7860-9), Incheon, Republic of Korea, October, 2010.

[5] J. Y. Beyon, G. J. Koch, and M. J. Kavaya "Data Acquisition and Processing System for Airborne Wind Profiling with a Pulsed, 2-Micron, Coherent-Detection, Doppler Lidar System," in Proc. of the Earth Science Technology Forum 2010, Arlington, VA, June, 2010.

[6] G.J. Koch, J.Y. Beyon, P.J. Petzar, M. Petros, J. Yu, B.C. Trieu, M.J. Kavaya, U.N. Singh, E.A. Modlin, B.W. Barnes, and B.B. Demoz, "Field Testing of a High-Energy 2-um Doppler Lidar," Journal of Applied Remote Sensing 4, 043512, 2010.

[7] K. Vermeesch, G. Koch, B. Gentry, T. Bacha, H. Chen, and B. Demoz, "Comparisons of Ground-Based, Radiosonde, and Aircraft Wind Measurements at the Howard University Beltsville Research Site," Wind Lidar Working Group Meeting, June, 2009.

[8] J. Y. Beyon, G. J. Koch, M. J. Kavaya, and M. Sahota, "Comparison of theoretical and empirical statistics of 
wind measurements with validation lidar (VALIDAR)," in Proc. of the Defense and Security Symposium 2008(6968-59), Orlando, FL, March, 2008.

[9] J. Y. Beyon, G. J. Koch, M. J. Kavaya, and M. Sahota, "Comparison of theoretical and empirical statistics of wind measurements with validation lidar (VALIDAR)," in Proc. of the Defense and Security Symposium 2008(6968-59), Orlando, FL, March, 2008.

[10] J. Y. Beyon and G. J. Koch, "Novel nonlinear adaptive Doppler-shift estimation technique for the coherent Doppler validation lidar," Optical Engineering, Vol. 46, No. 1, pp. 016002-1 - 016002-10, January 2007.

[11] J. Y. Beyon, G. J. Koch, and S. Ismail "Signal processing techniques for heterodyne differential absorption lidar," in Proc. of the Defense and Security Symposium 2007 (6567-53), Orlando, FL, April, 2007.

[12] G.J. Koch, J.Y. Beyon, B.W. Barnes, M. Petros, J. Yu, F. Amzajerdian, M.J. Kavaya, and U.N. Singh, "HighEnergy 2- $\mu m$ Doppler Lidar for Wind Measurements," Optical Engineering, Vol. 46(11), pp. 116201-1 116201-14, November, 2007.

[13] J. Y. Beyon and G. J. Koch, "Novel Nonlinear Adaptive Doppler Shift Estimation Technique (NADSET) for the Coherent Doppler Lidar System VALIDAR," in Proc. of the Defense and Security Symposium 2006 (62361), Orlando, FL, April, 2006.

[14] J. Y. Beyon and G. J. Koch, "Resolution Study of Wind Parameter Estimates by a Coherent Doppler Lidar System," in Proc. of the Defense and Security Symposium 2006 (6214-3), Orlando, FL, April, 2006.

[15] J. Y. Beyon and G. J. Koch, "Wind Profiling by a Coherent Doppler Lidar System VALIDAR with a Subspace Decomposition Approach," in Proc. of the Defense and Security Symposium 2006 (6236-5), Orlando, FL, April, 2006.

[16] J. Y. Beyon, G. J. Koch, and Z. Li "Noise Normalization and Windowing Functions for VALIDAR in Wind Parameter Estimation," in Proc. of the Defense and Security Symposium 2006 (6214-4), Orlando, FL, April, 2006.

[17] J. Yu, B.C. Trieu, E.A. Modlin, U.N. Singh, M.J. Kavaya, S. Chen, Y. Bai, P.J. Petzar, “1 J/pulse Q-switched 2 um solid-state laser," Optics Letters 31, 462-462, 2006. 